ISSN 1982-8713

\title{
Cultura Material do Japão no Período Kofun: um Panorama Introdutório
}

\author{
Material Culture of Japan in the Kofun Period: An Overview
}

\section{Larissa Bianca Nogueira Redditt ${ }^{1}$ \\ 1 Mestranda pelo International Master's Program in Japanese Humanities da Kyushu University (IMAP/Kōjinbungaku 広人文学). Mestre em Arqueologia pelo Programa de Pós-graduação em Arqueologia do Museu Nacional da Universidade Federal do Rio de Janeiro (PPGARQ-MN/UFRJ). E-mail: lariredditt@gmail.com.}

Recebido em 30 de julho de 2020; Aceito em 12 de dezembro de 2020.

DOI: $10.12957 /$ nearco.2020.57704

\section{Resumo}

O período Kofun (300-700 EC), classificado como proto-histórico, é crucial para a compreensão do processo de formação do Estado Japonês. No presente artigo, buscarse-á apresentar em termos introdutórios os principais elementos da cultura material deste período como foco em contextos funerários e ênfase nas variações temporais, compreendendo a cultura como algo dinâmico e não estático.

Palavras-chave: Japão; Período Kofun; Cultura Material.

\begin{abstract}
The Kofun period, classified as protohistoric, is crucial for the understanding of the Japanese state formation process. In this paper the main elements of the material culture of this period will be presented in an introductory manner, with a focus on funerary contexts and emphasis in temporal variations, understanding culture as dynamic and not static.
\end{abstract}

Keywords: Japan; Kofun Period; Material Culture.

\section{Introdução}

Durante o período Kofun (kofun jidai 古墳時代), foi construído no arquipélago japonês um grande número de tumuli (ver figura 1), hoje chamados de kofun 古墳, ou 
NEARCD: Revista Eletrônica de Antiguidade 2020, Volume XII, Número II - ISSN IS882-8713

Núcleo de Estudas da Antiguidade - NEA

Universidade do Estado do Rio de Janeiro

ISSN 1982-8713

túmulo antigo. Muitos sobreviveram ao tempo 202 - embora uma parte destes tenha sido modificada ${ }^{203}$ - sendo preservados em meio a grandes cidades completamente urbanizadas, o que mostra a sua importância para os japoneses. Os kofun são tão significativos para a história japonesa que deram nome ao período durante o qual foram construídos. ${ }^{204}$

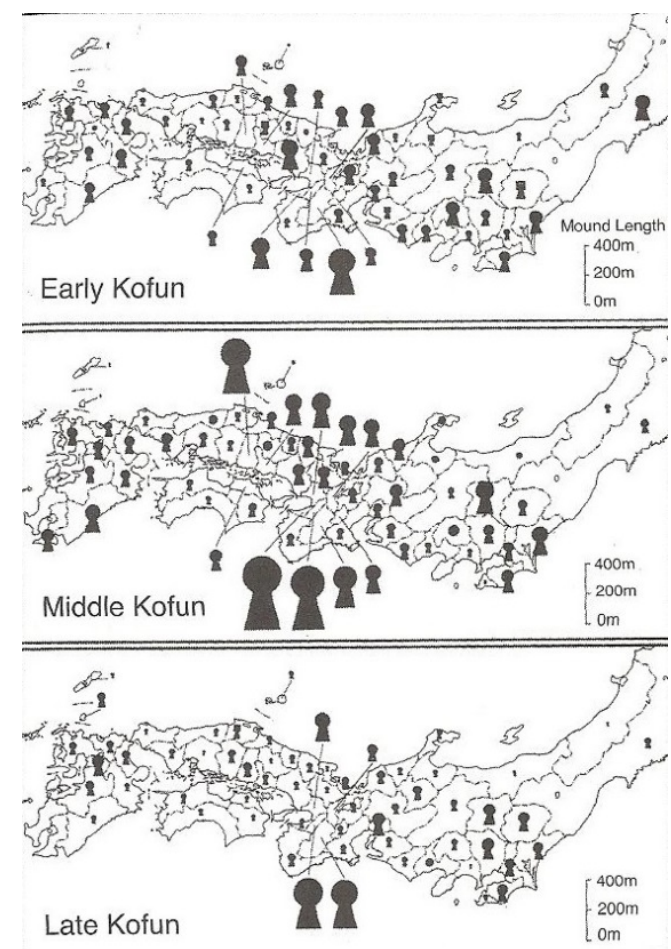

Figura 1: Mapa demonstrativo da proporção e quantidade de kofun para cada região do arquipélago japonês nas três fases do período (MIZOGUCHI, 2013: 298).

\footnotetext{
${ }^{202}$ Cerca de 160.000. Muitos outros foram destruídos pela ação do tempo ou pela ação humana. Deve-se considerar também que ainda há muitos que não são conhecidos e estão ainda por ser descobertos.

203 "In both the Tokugawa and Meiji periods, repairs to the royal tumuli were undertaken to gain validity for the political regimes and also to protect the tombs from agricultural development by peasants who were suffering from economic difficulty. The repairs often changed the outer configurations of the tombs. In some cases, the mounds were made higher, new moats were excavated, tombs were combined to form keyhole-shaped mounds." (Pearson, 1992: 120).

204 O presente artigo é uma adaptação de partes selecionadas da dissertação de mestrado da autora, defendida em 2017 junto ao PPGARQ-MN/UFRJ.
} 
A datação mais comum para o período Kofun (ver figura 2) se estende de meados século 3 EC 205 ao final do século 7 (MIZOGUCHI, 2013: 34), embora haja variações. Para fins de facilitar a interpretação do período, há também uma subdivisão em três fases, embora estas também possam variar conforme o aspecto em que se foque.

\begin{tabular}{|l|l|l|}
\hline \multicolumn{2}{|l|}{ PERÍODO } & DATAÇÃO \\
\hline \multicolumn{2}{|l|}{ Yayoi } & 300 AEC - 250 \\
\hline \multirow{3}{*}{ Kofun } & Inicial & $250-400$ \\
\cline { 2 - 3 } & Médio & $400-475$ \\
\cline { 2 - 3 } & Tardio & $475-710$ \\
\hline Nara & $710-794$ \\
\hline
\end{tabular}

Figura 2: Tabela de cronologia (adaptada e traduzida de BARNES, 2010: 9)

Por se tratar de um tema inédito na academia brasileira, o objetivo do presente artigo é apresentar um panorama introdutório do período, que funcionará como um primeiro contato dos leitores brasileiros e quiçá estimulará o interesse em pesquisar mais a fundo sobre o período.

Ao considerarmos os kofun e o período no qual foram construídos, inúmeros questionamentos surgem diante destas estruturas. No presente artigo focaremos em investigar se estas estruturas permaneceram inalteradas em sua forma de construção desde quando começaram a ser construídas até seu declínio.

\section{Processo de centralização}

No período Kofun se iniciou o processo de centralização do Estado Japonês e o desenvolvimento do sistema imperial, processo este que somente se completou na

\footnotetext{
205 Todas as datas contidas neste artigo são EC (Era Comum), salvo aquelas explicitadas de outra forma.
} 
passagem deste período para o seguinte, o período Nara (cf. figura 2). Durante todo este período, houve contatos intensos com o Continente (China e Península Coreana).

Indo na direção contrária de paradigmas tradicionais estabelecidos, Mizoguchi (2013: 215) aponta que os primeiros kofun foram construídos perto demais uns dos outros para serem túmulos de chefes "governando" uma região. Ao invés disso, diversos chefes competiam pela influência sobre a região. Os maiores kofun de cada região não formam uma sequência genealógica, o que indica que a chefia mudava de mãos entre grupos que competiam.

O início do período Kofun foi caracterizado pela adoção de um "pacote inicial," que incluía: enterramentos de tipo tumulus em formato de fechadura; espelhos de bronze; ferramentas e armas de ferro e bronze; cova da câmara mortuária de pedra; ítens de jaspe e tufo verde.

Ainda no período Yayoi, os moradores das vilas de tipo porto-de-comércio, vindos de lugares remotos, eram mediadores entre a Península e as comunidades agrárias do interior, e nessas vilas foram encontrados vestígios de pessoas enviadas para fazer trocas de produtos importados, o que gerava a necessidade de convivência entre culturas diferentes nestes espaços (MIZOGUCHI, 2013: 219). Esta convivência foi essencial para a forma como os itens do Pacote Kofun foram trazidos e ressignificados no Japão. Os kofun e o conjunto funerário enquanto horizonte comunicativo (mortuário) da elite foram gerados em meio à essa necessidade de desenvolver um sistema compartilhado de valores e códigos de conduta. Isso é corroborado pelo fato de que a distribuição geográfica dos primeiros kofun coincide com a dos portos de comércio (como Hashihaka, por exemplo) e se espalha para o Norte (MIZOGUCHI, 2013: 220, 221).

É importante destacar que a adoção do pacote inicial não resultou no fim imediato das práticas mortuárias regionais anteriores em todas as áreas, embora o desaparecimento dos itens característicos dos horizontes rituais do Norte de Kyūshū e de Kansai tenham sido abruptos e pareçam coincidir com o início dos tumuli em formato de fechadura (MIZOGUCHI, 2002: 200, 204). 
Devido à sua localização privilegiada, a dominação da região central de Kinki sobre os contatos com o continente se intensificou durante o período Kofun inicial e médio, e constantemente adicionava novos itens ao pacote mortuário. O domínio das elites de Kinki sobre as demais regiões já estava estabelecido de forma bastante estável ao final do período Kofun.

Os montes funerários já existiam desde o período Yayoi, porém o conjunto funerário em seu interior era equipado de forma diferente (MIZOGUCHI, 2013: 224, 225). Kondō $(1986: 335,336)$ delimita quatro fatores que caracterizam o que podemos chamar de Complexo Funerário Kofun. Todos estes quatro fatores são inovações em relação aos enterramentos em tumuli do Yayoi.

(1) O tumuli é redondo, com topo achatado é uma projeção quadrada na frente. Nos montes maiores, o monte principal é sempre redondo, mas em exemplares menores pode ser quadrado. Nos mais antigos, a projeção frontal é trapezoidal.

(2) O enterramento era feito numa cova cavada no topo do monte principal, onde era depositado um caixão de madeira (geralmente Cedro) escavada, em torno do qual era construída uma câmara de pedra com laje de rocha fendida. O caixão podia medir de 4 a 8 metros.

(3) Bens funerários: eram depositados dentro do caixão e ou no seu entorno. Incluíam espelhos (da dinastia Han posterior, dos quais os de borda triangular eram os mais populares), armas de metal (principalmente ferro) como adagas, espadas, alabardas e pontas de flecha, armaduras, aljavas, ferramentas de agricultura, equipamento de pesca e ocasionalmente contas circulares.

(4) Exterior: os montes geralmente eram cobertos com pedras (figura 3.1). Recipientes de argila contendo oferendas simbólicas de comidas e bebidas para o morto chamados haniwa eram colocados em cima e em torno do tumulus. 


\section{Definição}

Mas o que é, afinal, um kofun? A palavra á formada por dois kanji206: 古 (velho, antigo) e 墳 (túmulo) (KIDDER, 1970: 149). Tratam-se de monumentos funerários de tipo tumulus (burial mound), neste caso, um dólmen de pedra encimado por um monte artificial de terra, por vezes coberto por pequenas pedras, cercados por um fosso. Nem todos os membros da comunidade eram enterrados em kofun: a maioria era enterrada em covas comuns, e destes não restaram vestígios, por conta do alto nível de acidez do solo japonês, que não é favorável à preservação de materiais orgânicos a longo prazo (MIZOGUCHI, 2013: 201). Os ocupantes dos kofun eram pessoas de alguma relevância regional. A maior parte das pessoas era enterrada em covas comuns com caixões simples de madeira (ver figura 3).

O que há de mais peculiar e distintivo nos kofun é seu formato, do qual há pelo menos quatro variantes (fig. 3).

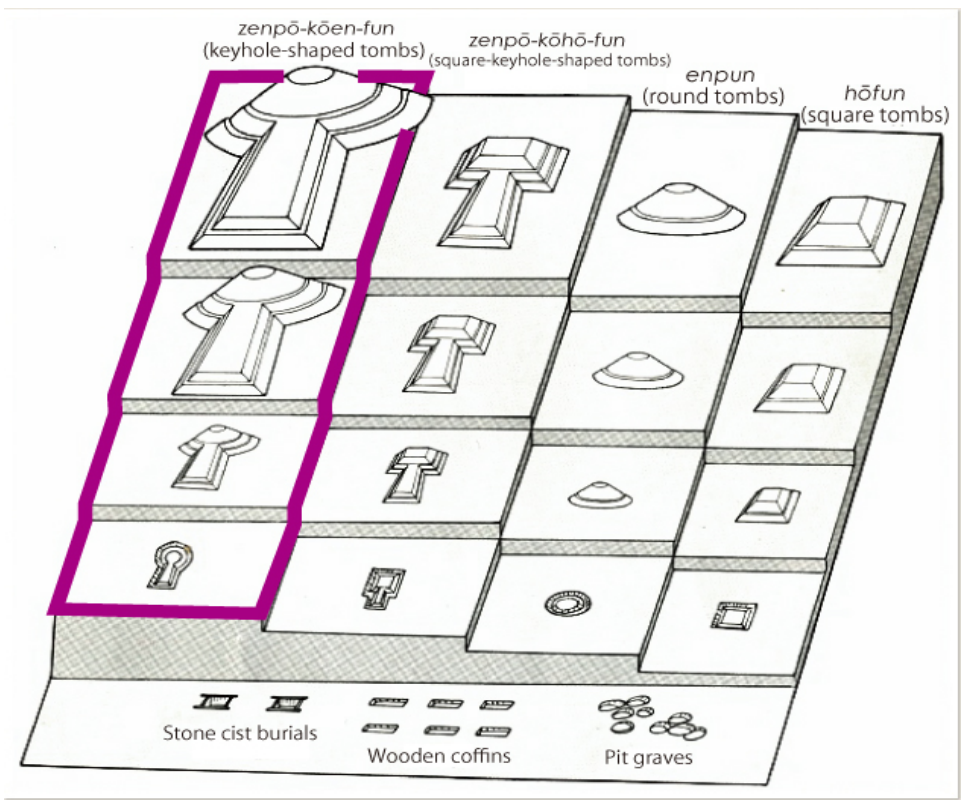

Figura 3: Quadro demonstrativo dos diferentes formatos e tamanhos de kofun (Barnes, 2010: 8)

\footnotetext{
${ }^{206}$ Ideogramas que são parte do sistema de escrita japonês.
} 
Apesar da existência de variações, o mais conhecido, inclusive por ser o formato dos maiores kofun, é o de fechadura (zenpō kōen 前方後円), redondo atrás, com uma extensão retangular na frente. Há ainda outros formatos, encontrados em túmulos menores, como são o redondo (enpun 円墳), o quadrado (hōfun 方墳), e o que é quadrado atrás e retangular na frente (zenpō kōhō 前方後方).

A câmara funerária localiza-se sempre na parte de trás do monte, ou seja, na parte redonda do zenpō kōen e a quadrada do zenpō kōhō. O monte frontal trata-se de um apêndice, embora haja casos rasos de enterramentos secundários feitos nesta parte do monte.

Em relação aos materiais utilizados e dimensões dos montes e das câmaras, não é possível delimitar um único grupo de materiais que dê conta de representar todos os tumuli, pois a variação regional e temporal é grande demais. Ao invés disso, utilizarei o esquema de Aikens e Higuchi (1982) para apresentar as informações acerca dos materiais. Aikens selecionou um pequeno número de tumuli que segundo ele, se vistos em comparação com os outros construídos no mesmo subperíodo do período Kofun, podem ser considerados representativos daquele subperíodo, guardadas as devidas proporções. Esta forma de análise, embora apresente limitações, atende às necessidades da presente investigação e se apresenta como alternativa à tarefa impossível no espaço de um artigo - de dar conta das especificidades dos materiais de cada kofun que foi construído. Os exemplares selecionados serão apresentados nas seções correpondentes a cada fase.

\section{Características gerais}

Dentre os bens funerários cuja presença perpassa todo o período, destacam-se os haniwa. Eles estiveram presentes desde a aurora do período Kofun, e foram encontrados até mesmo nos tumuli mais antigos já identificados. Os primeiros haniwa tinham formato de cilindros - primeiro simples e depois mais elaborados. 
Posteriormente, começou-se a produzir modelos com outros formatos, como casas, aves e outros animais, etc. Os últimos formatos a aparecer foram os humanos, que chegaram a conhecer um alto grau de detalhamento com o tempo, como a diferenciação não apenas de gênero, mas também de variadas ocupações e vestimentas.

Feitos pela mesma tradição da cerâmica haji, que existia no arquipélago desde o período Yayoi, os haniwa são estatuetas de argila vermelha, porosa e cozida por meio de um processo de cozimento a baixas temperaturas (BARNES, 1974: 9). Eram moldados a partir do método de enrolamento ou sobreposição de anéis. O que os diferencia dos recipientes haji funcionais é que possuem furos em suas bases, o que demonstra que nunca foram destinados para um uso utilitário, já que os furos eram feitos durante as etapas iniciais da confecção, antes mesmo do cozimento (MIKI, 1974: $16,17)$.

$\mathrm{Na}$ metade do século 5, observou-se o aparecimento de um novo tipo de cerâmica no arquipélago: a cerâmica sue (須恵器), que era feita através de um método de cozimento em altas temperaturas, com coloração acinzentada, semelhante ao tipo de cerâmica utilizada na península coreana nos séculos V e VI. Haniwa de cerâmica sue começaram a ser produzidos, embora não tivessem formas próprias (ou seja, diferentes das formas encontradas em haniwa de cerâmica haji) (BARNES, 1974: 12).

Para Mizoguchi, este processo foi realizado por pessoas aceitando e obedecendo autoridade embora reconheça que é improvável que as pessoas tenham sido coagidas a trabalhar, e que o mais provável é que tenham se voluntariado para a construção. Essa teoria é sustentada pelo fato de que a supremacia militar e econômica da região de Kansai só foi estabelecida no fim do "Earlier Kofun" (fim do século V), quando já havia muitos kofun construídos (MIZOGUCHI, 2002: 199).

Considerando que o processo de construção exigia vasta força de trabalho, e levando em conta o número estimado dos habitantes por comunidade, fica claro que a construção de mais de um kofun simultaneamente teria significado uma divisão de lealdades. Sendo que foram construídos kofun de tamanhos semelhantes em locais 
NEARCD: Revista Eletrônica de Antiguidade 2020, Volume XII, Número II - ISSN IS82-8713

Núcleo de Estudas da Antiguidade - NEA

Universidade do Estado do Rio de Janeiro

ISSN 1982-8713

diferentes, torna-se possível contrariar a tese da centralização precoce, ainda mais considerando que a regionalização das características dos kofun era grande demais para sustentar uma centralização (MIZOGUCHI, 2013: 239, 240) como a proposta por aqueles que advogam a teoria do Yamato Seiken.

\section{A cultura material em três fases: Período Kofun Inicial (séculos 3 e 4)}

No final do período Yayoi, os enterramentos eram feitos geralmente em covas contendo caixões de madeira. No início do período Kofun, os tumuli costumavam ser construídos nos pés de montanhas ou no declive de uma colina. $\mathrm{O}$ apêndice frontal tendia a ser um retângulo cuja altura diminuía na medida em que se afastava da câmara funerária.

As câmaras funerárias desta fase são de tipo vertical, ou câmara de cova (tateanashiki sekishitsu 竪穴式石室), construídas a partir de uma cova rasa no topo da parte circular do monte após este já ter sido erguido. Arenito era o tipo de rocha mais comum para a construção das paredes. O resultado pode ser observado nas imagens a seguir (figs. 4 e 5 ).

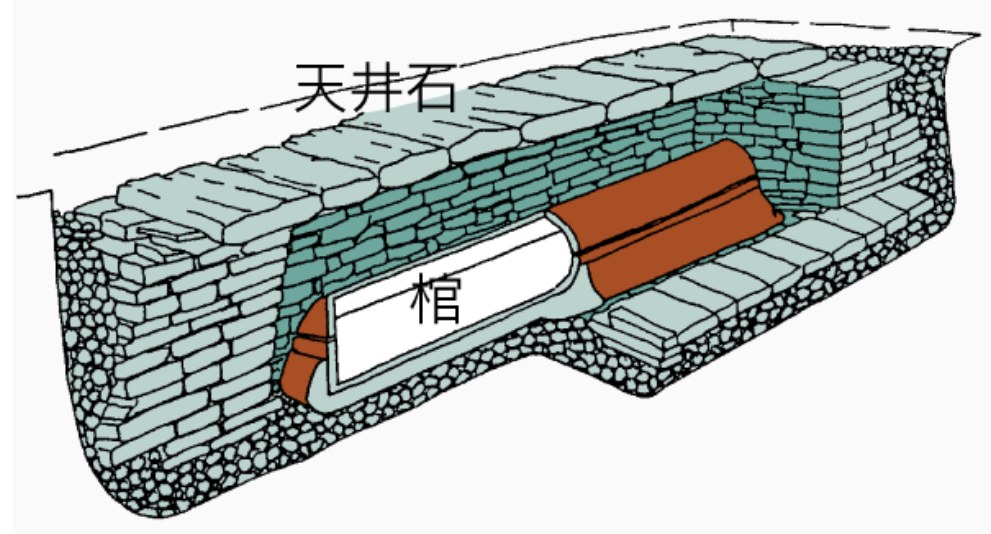

Figura 4: Modelo de câmara de tipo cova. Disponível em: ranhaku.com/web04/c4/4_05.html. Acesso em: 31 de julho de 2020. 


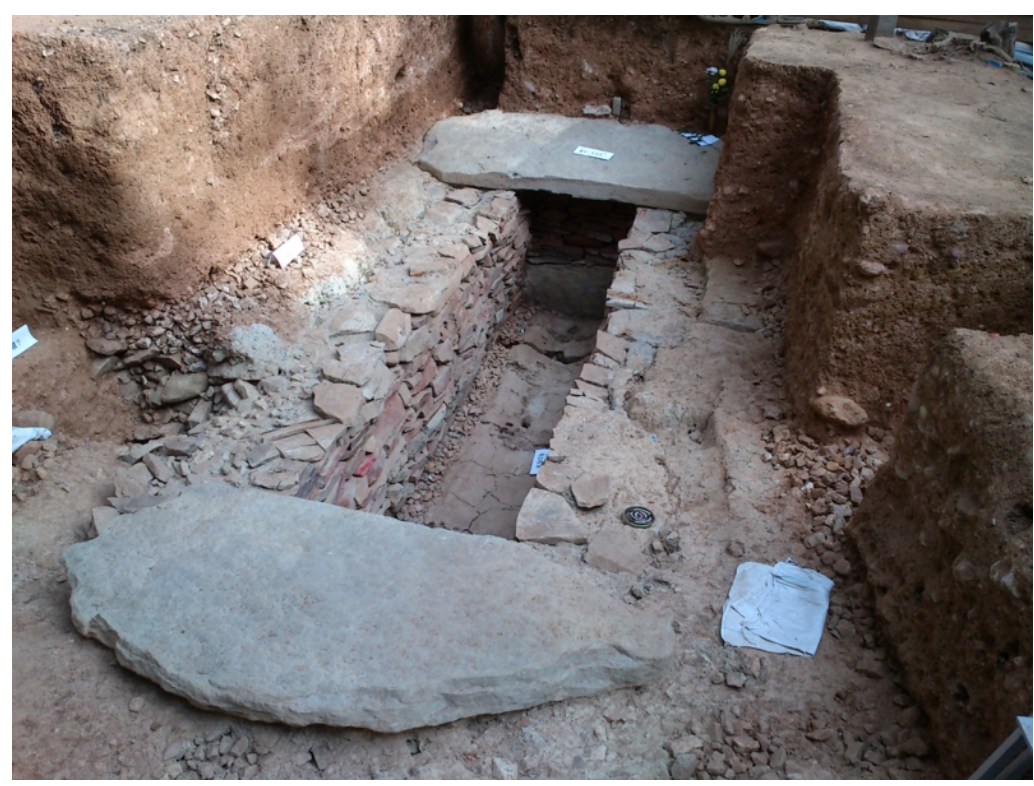

Figura 5: Fotografia de camâra de tipo cova. Disponível em: f.hatena.ne.jp/gashatech/20121005143116. Acesso em: 31 de julho de 2020.

Alguns kofun que exemplificam o estilo do século 4 são Ōtsukayama, Hashihaka, e o kofun do imperador Sujin. Os exemplares deste período apresentam formato de fechadura, quadrado ou circular e são, em muitos casos, escalonados. Seu interior consiste de uma câmara de pedra de estilo cova ou um caixão de madeira envolto em argila, também localizado em uma cova no topo do monte.

Dentre os bens funerários encontrados neste período, temos ornamentos em jaspe, espelhos importados do continente decorados com motivos dos Quatro Deuses, outras deidades ou animais e objetos de uso ritual que já eram utilizados desde o período Yayoi, como braceletes de pedra, e contas cilíndricas.

Neste momento inicial é muito comum a presença de ferramentas ligadas à prática da agricultura como foices, machados, plainas e facas. Havia também algumas armas, como pontas de flechas feitas de bronze e ferro, espadas de ferro, adagas e pontas de lança.

Por volta da metade do século 4, armaduras passaram a fazer parte dos bens funerários. Espelhos produzidos no Japão passam a aparecer no lugar dos espelhos 
importados do continente. Os bens de uso ritual diminuem em número e em qualidade, enquanto que o número de armas aumenta. Exemplos representativos neste momento são Nyōtanyama, Uedono, Muromiyayama (OKAUCHI, 1986: 142)

Com relação à fase inicial do período, Mizoguchi afirma que a construção dos kofun era uma importante ocasião cerimonial, que envolvia a participação de inúmeras comunidades, algumas de lugares distantes (MIZOGUCHI, 2013: 239, 240), o que é um indício sustentador da hipótese de que as relações no Kofun inicial se davam em forma de rede em que cada comunidade era um nó.

Tsubai Ōtsukayama Kofun (AIKENS; HIGUCHI, 1982: 255-263) é considerado um kofun típico da fase inicial do período. Localizado na planície do Rio Kizu, foi aberto por conta da construção de uma ferrovia em 1894 e escavado por Higuchi em 1953 por conta de outra obra no local. Este tumulus é do tipo zenpō kōen, ou seja, possui a parte da frente do monte em formato retangular e a parte de trás em formato circular, assemelhando-se a uma fechadura. A parte redonda foi construída em uma elevação já existente no cume de uma montanha enquanto a parte da frente foi feita a partir de um pedaço da encosta do cume. Possuía um fosso seco e suas dimensões eram de 185 metros de comprimento por 75 metros de largura.

Sua câmara funerária era de tipo câmara subterrânea, longa e estreita, construída numa cova profunda de 4,9 metros de comprimento, 1,1 metro de largura e 3 metros de altura, cujo chão ficava 4 metros abaixo da superfície do monte. As paredes da câmara foram feitas de placas achatadas de pedra, sem argamassa, acima de uma camada de cascalho. Também foi derramado cascalho entre as paredes de pedra e nas laterais da cova. O chão da câmara foi pavimentado com argila, com uma depressão no local destinado para o caixão. O teto foi feito com 8 placas de pedra sobre as laterais das paredes cobertas por uma camada de argila. A câmara se manteve seca e bem preservada até ser danificada pelas obras da ferrovia, entretanto do caixão de madeira só sobraram fragmentos e não restaram rastros de seu ocupante. 
ISSN 1982-8713

Não há evidências de oferendas dentro do caixão, mas foram encontrados inúmeros artefatos organizados ao longo das paredes da câmara. Dentre eles há uma proeminência de armas e outros artefatos de guerra como espadas de ferro de 90 centímetros, pontas-de-lança ou facas de 45 centímetros, pontas de flechas de ferro e bronze, fragmentos de capacete de ferro e placas de armadura de ferro. Foram encontrados também: ferramentas de ferro, como foices, pontas de machado e enxó, cinzel para madeira e facas de talhar madeira; arpões farpados de ferro, lanças de pesca e um anzol; 30 espelhos de bronze manufaturados na China (da última metade do século 3), colocados ao longo das laterais e cabeceira da câmara funerária, e mais três espelhos que foram enterrados separadamente.

\section{Período Kofun Médio (século 5)}

A partir do século 5, a construção dos montes passa a ser realizada em terraços planos ou planícies, como pode ser observado nos kofun designados como túmulos de Ōjin e Nintoku. O tamanho dos tumuli desta fase pode alcançar até 400 ou 500 metros de comprimento. $\mathrm{O}$ apêndice frontal passou se assemelhar a um trapézio, em que a parte mais distante da câmara era mais larga e mais alta, podendo até mesmo exceder a altura do monte traseiro. Os haniwa de formato humano começam a aparecer na segunda metade do século 5.

Neste mesmo século começam também a aparecer exemplares da cerâmica sue, em lugar dos contêineres de jaspe e da cerâmica de tipo haji. A técnica da cerâmica sue, na qual as peças são cozidas a mais de $1000^{\circ} \mathrm{C}$ tem origem nos reinos coreanos de Kaya e Silla, tendo chegado no arquipélago por volta da metade do século 5, data estimada pela aparição dos primeiros fornos utilizados para esta técnica. Neste momento, surge algo novo nos conjuntos de bens funerários: aparatos de cavalo (bridões, estribos, sinos e acessórios de sela).

Em meados do século 5, em tumuli como Ōtami, Nagamochiyama, Kokuzuka, Kamo-Inariyama e Kinkaki, observa-se a adição de ornamentos de correias de cavalo de 
NEARCD: Revista Eletrônica de Antiguidade 2020, Volume XII, Número II - ISSN IS882-8713

Núcleo de Estudas da Antiguidade - NEA

Universidade do Estado do Rio de Janeiro

ISSN 1982-8713

tipo e armaduras. Ornamentos como cintos e brincos de ouro também aparecem pela primeira vez nos conjuntos funerários.

Na segunda metade do século 5, câmaras de pedra horizontais com entradas laterais, que já eram comuns em Paekche e Kaya, começam a aparecer em alguns lugares do arquipélago. Entretanto, não se tornam comuns de imediato. É só a partir do século 6 que este tipo de câmara começa a ser usado nas "tumbas imperiais 207" (OKAUCHI, 1986: 142,143).

Este estilo de câmara de tipo galeria ou corredor (yokoanashiki sekishitsu 横穴 式石室), que era construída a partir do chão junto com o monte, conforme pode ser observado nas imagens abaixo (figs. 6 e7).

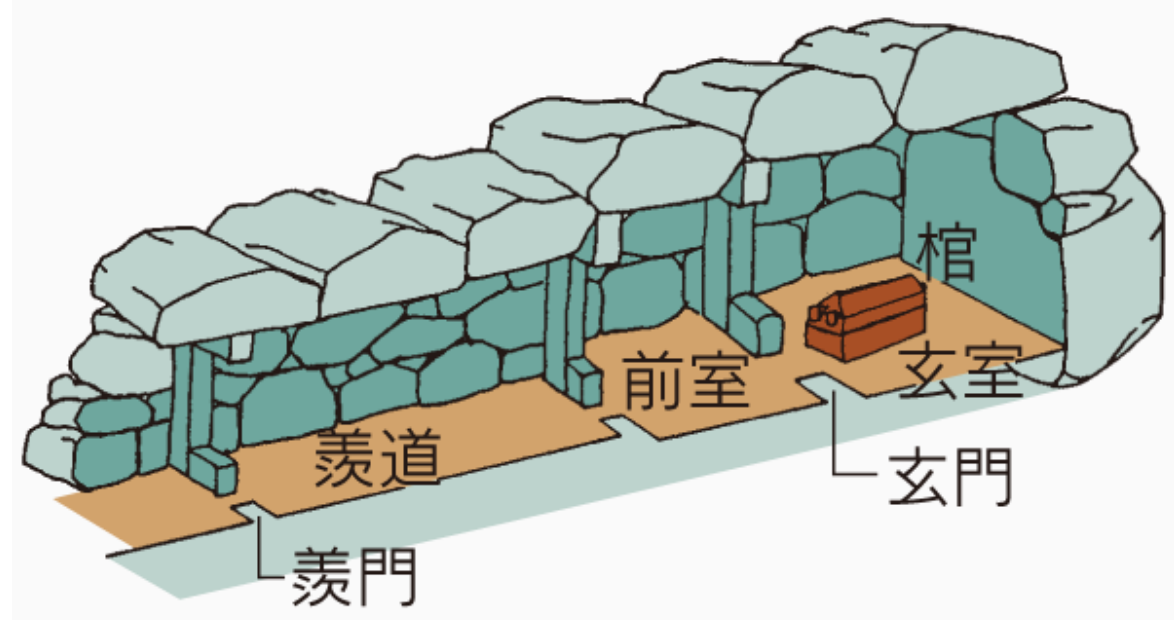

Figura 6: Modelo de câmara de tipo galeria. Disponível em: ranhaku.com/web04/c4/4_05.html. Acesso em: 31 de julho de 2020.

207 Túmulos associados à linhagem imperial. Entretanto, o sistema de designação destes túmulos é controverso e já provou diversas vezes ser falho. 


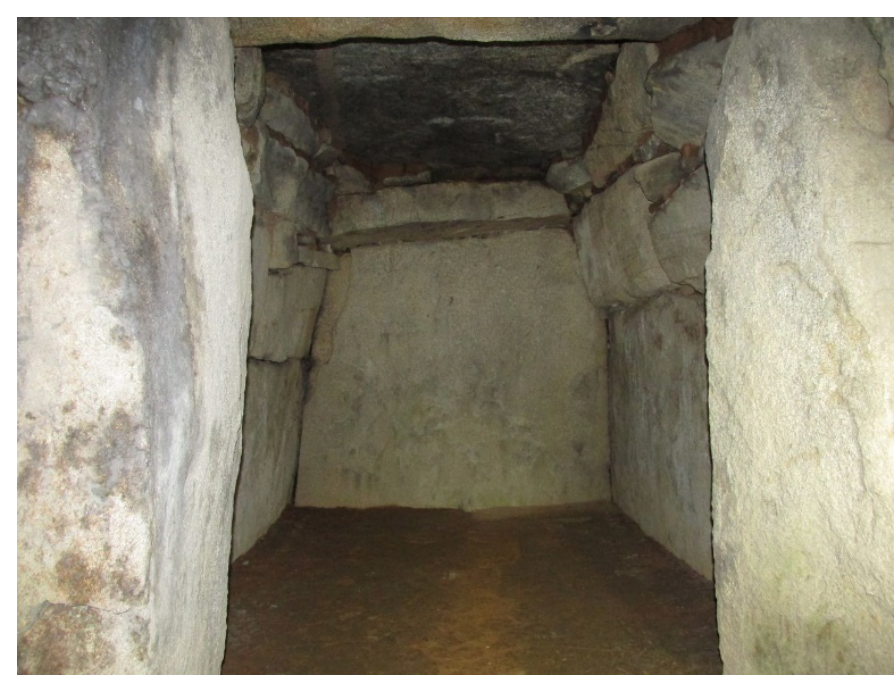

Figura 7: Fotografia de câmara de tipo galeria. Disponível em: livedoor.blogimg.jp/warabite/imgs/6/6/66bee055.jpg. Acesso em: 31 de julho de 2020.

Muro Miyayama Kofun (AIKENS e HIGUCHI, 1982: 275-277), localizado na planície de Yamato, em Katsuragi, data da primeira metade do século 5 e é representativo dos kofun da fase média do período. Vale ressaltar que a datação foi realizada com base no tipo de sítio onde se localiza (junção de Colina com planície) e pelo formato dos montes traseiro e frontal, que são equivalentes. Suas dimensões são: 238 metros de comprimento por 110 metros de largura.

Sua câmara funerária, de tipo subterrâneo, mede 5,5 metros de comprimento 1,9 metro de largura e 1 metro de altura, feita de alvenaria de pedra seca (técnica de construção em que não é usado nenhum tipo de argamassa entre as pedras). Em seu interior foram encontrados haniwa de aves aquáticas e outros. O teto foi feito utilizando 5 pedras tabulares, colocadas em cima das paredes. As paredes e o teto foram revestidos por fora com uma camada grossa de argila. Contava com um caixão de pedra composto, em forma de baú. O caixão foi composto com 6 placas grandes de pedra, sem argamassa para juntá-las. A tampa possui 8 painéis separados por margens em baixo relevo.

Como a câmara já havia sido saqueada antes da chegada dos arqueólogos, muita coisa se perdeu, e apenas alguns artefatos remanesceram. Foram encontradas 
armaduras e espadas de ferro, bem como outras lâminas, e imitações feitas de pedra; fragmentos de espelhos de bronze de tipo Han; 600 magatama de talco e outras contas (um número anormalmente alto de magatama, um tipo de conta curva de uso ritual); haniwa muito variados, tais como casas, guarda-chuvas, armaduras, escudos, aljavas, etc. acima de cada enterramento. ${ }^{208}$

\section{Período Kofun Tardio (séculos 6 e 7)}

No século 6, os tumuli voltam a ser construídos em locais elevados, com formato principalmente de fechadura ou circular. Neste momento, as câmaras de estilo horizontal já haviam substituído completamente as câmaras de estilo cova. Isso significa que os interiores eram agora mais espaçosos (OKAUCHI, 1986: 143).

Os tumuli ainda tinham dimensões gigantescas e bens funerários de qualidade altamente luxuosa estão presentes na maior parte dos grandes exemplares, como Hōanzuka, monte n․ 3 em Tamakiyama, Iwatoyama e Eta-funayama. Ornamentos de ouro, como coroas, armaduras e aparelhagem de cavalo também estão presentes (OKAUCHI, 1986: 143). No período Kofun tardio em geral, há um embelezamento do corpo do chefe, e ele passa a usar uma coroa (MIZOGUCHI, 2002: 219).

Como a estrutura da câmara horizontal não permitia uma altura de monte tão elevada quanto a câmara de cova permitiria, por conta do peso que não seria suportado pelas paredes e teto, os montes passaram a ser cada vez menores.

Na metade do século 6, os tumuli passam a ser construídos em aglomerados geralmente localizados em colinas e na subida de montanhas. As câmaras com entrada lateral facilitam os enterramentos múltiplos, com o que surgem tumbas familiares.

Após o século 7, a construção de tumuli no Japão diminui drasticamente. Tumbas imperiais se tornam quadradas, semelhante às construídas pelas dinastias chinesas Sui

\footnotetext{
${ }^{208}$ Existe evidência de que um segundo complexo funerário teria existido neste kofun, porém ele foi completamente perdido. Kofun com dois ou três enterramentos eram relativamente comuns para esta época.
} 
e Tang. Tumuli como Ishibutai-Monjuin Oeste e Iwayayama utilizam pedra de corte fino para a câmara. Koganezuka e Maitani possuem pedra cortada em imitação a tijolos, enquanto que Abeyama tem tanto tijolos quanto pedra. Takamatsuzuka, desta mesma época, se tornou famoso por suas pinturas.

O túmulo atribuído ao Priíncipe Shōtoku, datado de 621 é um tumulus circular com fileiras de pedra na base e com câmara de pedra cortada com entradas laterais. 0 tumulus designado como pertencendo ao imperador Tenmu tem sido aceito pelos arqueólogos como o último esforço de construção de tumuli, marcando o final do período Kofun. Esta tumba é datada do final do século 7 (OKAUCHI, 1986: 143, 144). Após o enterramento duplo de Tenmu e Jitō, a cremação se torna mais comum, pelo menos para a linhagem imperial.

Udozuka Kofun (AIKENS e HIGUCHI, 1982: 277-279), datado da metade do século 6, é um exemplar representativo do momento final do período Kofun. Localizado no Vale do Rio Yamato, aproveita uma elevação natural. Mede 60 metros de comprimento, 30 metros de largura e 12 metros de altura. Sua câmara funerária é de tipo galeria, com entrada para um corredor de 8,3 metros de comprimento, 2,7 metros de largura e 2 metros de altura, com sistema de drenagem para manter o túmulo seco. Este corredor havia sido fechado por pedras grandes na entrada, e se estende a partir da parte de trás do kofun. A câmara funerária está localizada abaixo do centro do monte traseiro. As dimensões da câmara são: 2,7 metros de largura, 6 metros de comprimento e 4,3 metros de altura. Seu teto foi construído com duas placas gigantes de pedra, e as paredes a base de placas de pedra massivas e acima delas havia duas ou três fileiras desiguais de seixos. Foram encontrados traços de dois caixões de pedra compostos com laterais de placas de pedra, um dos quais estava no corredor. Porém, o kofun havia sofrido pilhagem.

Foram encontrados artefatos em três lados do caixão principal: arreios de cavalo, equipamento militar (alabardas, espadas de ferro curtas e longas, dois arcos de madeira, 138 Pontas de flecha), adornos (anéis de contas de vidro enquanto as do período Kofun inicial eram de pedra), um espelho de bronze, oferendas de cerâmica numerosas e 
ISSN 1982-8713

variadas, jarras, tigelas, pratos, tigelas com pedestais, travessas cobertas, recipientes compostos (cerâmica de mesmo tipo foi encontrada em torno do outro no caixão o que mostra que os dois instrumentos foram contemporâneos). No corredor foram achados haniwa de casas, guerreiros e armadura e fragmentos de haniwa em diversos lugares em cima do túmulo. Ressalta-se que este kofun foi usado como local de cerimônias no século 12.

Shimanosho Ishibutai Kofun (AIKENS; HIGUCHI, 1982: 282-284) é um exemplo típico da segunda metade do período Kofun tardio, datado da primeira metade do século 7. Localizado na região de Asuka, na bacia de Nara é um tumulus de tipo megalítico. Sua câmara funerária de tipo galeria foi feita de pedra, com passagem de entrada de 12,5 metros de comprimento, 2 metros de largura e 2 metros de altura, que leva a uma câmara maior e mais alta. Sua escala é maior e mais massiva que as do fim do século 6.

O dólmen que abriga a câmara funerária mede 22 metros de comprimento e 7 metros de altura. $O$ interior da câmara mede 8 metros de comprimento, 3,5 metros de largura e 5 metros de altura. $\mathrm{O}$ corredor foi equipado com sistema de drenagem. $\mathrm{O}$ túmulo foi feito com pedras gigantescas, e por isso muito pesadas - de granito - cuja pedreira ficava a 3 quilômetros de distância. $O$ transporte das pedras deve ter requerido centenas de pessoas, gado, cavalos e levado meses. Isso é importante porque mesmo que no período Kofun tardio os montes fossem menores, as câmaras eram maiores e muito mais trabalhosas de construir.

Foi feita uma plataforma de terra de 66 metros quadrados, e em cima desta plataforma o dólmen foi construído, e depois coberto pelo monte, que deve ter sido em forma de domo ou retangular. O tumulus possuía fosso quadrado, que era a origem da terra usada para construção do monte. Como foi saqueado cerca de mil anos atrás, não restou caixão e os fragmentos de artefatos encontrados eram uma mistura confusa de cerâmica haji, objetos de bronze do período Nara e Heian e moedas Tokugawa, o que 
ISSN 1982-8713

indica que provavelmente foi saqueado no século IX e usado como abrigo e ou santuário local.

Takamatsuzuka Kofun (AIKENS; HIGUCHI, 1982: 284, 285), o último kofun a ser analisado, faz parte de um grupo de kofun na vila de Asuka, e data da última parte do período Kofun, perto da transição para o período Nara, momento em que os tumulus em forma de fechadura já não eram mais construídos. Seu monte é pequeno e redondo com 18 metros de diâmetro e 5 metros de altura. A câmara funerária também é pequena e retangular, feita de placas de pedra, com entrada em uma das pontas.

Nas paredes da câmara funerária havia pinturas, o que já existia desde o século $\mathrm{VI}$, primeiro em Kyushu e depois em todo o arquipélago, embora ainda não fosse comum. No teto havia uma constelação estelar; na parede Leste, o sol e um dragão azul no centro, ladeados por quatro homens de um lado e quatro mulheres do outro; na parede Oeste, a lua e um tigre branco, ladeados por quatro homens e quatro mulheres; na parede Norte, o espírito tartaruga-cobra; e na parede Sul, a figura se perdeu. As figuras mostram os animais tradicionais das quatro direções, o que leva a crer que houvesse uma fênix vermelha na parede Sul. Quanto ao conteúdo da câmara, foi quase todo saqueado. O caixão era de madeira com laca, e foram encontrados pratos decorativos e um espelho de estilo T'ang.

\section{Considerações finais}

Após observar exemplares de três diferentes momentos do período Kofun, fica claro que estas estruturas não se mantiveram inalteradas através do tempo no que diz respeito às suas principais características e forma de construção.

Apesar de algumas características estarem sempre presentes, diversos elementos, como o próprio formato do monte, tipo de câmara funerária e tipo e quantidade de bens funerários sofreram alterações significativas ao longo do período Kofun. Os montes sofreram alterações em seu tamanho e formato. Se tornaram muito maiores no Kofun médio se comparado ao inicial, e depois voltaram a ser menores, 
porém havendo uma grande diferença de tamanhos entre aqueles de Kinki e os de outras regiões. Já o apêndice frontal sofreu grande alteração de formato, passando de retangular a trapezoidal, com a ponta mais alta que o monte traseiro.

A câmara funerária, que inicialmente era construída de forma semelhante a uma cova no topo do monte, passou a assumir um estilo muito mais monumental no Kofun médio, tendência esta que se acentuou mais ainda com o passar do tempo, mesmo que o tamanho do monte em si tenha diminuído. O acesso permanente ao morto foi proporcionado com este novo tipo de câmara.

As mudanças nos bens funerários talvez tenham sido as mais significativas dentre as alterações. O conjunto de bens, que inicialmente incluía principalmente ferramentas de atividades cotidianas comuns e ítens rituais de pedra e em menor medida, de bronze, passa a incluir cada vez mais ítens bélicos a partir do Kofun médio e estes chegam a ocupar a maior proporção dentro do conjunto no Kofun final, quando este conjunto como um todo se apresenta com caráter indivudual e biográfico, em oposição ao caráter comunitário que havia anteriormente.

A interpretação do significado de cada uma mudança, entretanto, foge ao escopo deste artigo por questões práticas de espaço, e se coloca como um empreitada futura, a ser retomada em uma próxima publicação.

\section{Referências bibliográficas}

AIKENS, C. Melvin; HIGUCHI, Takayasu. Prehistory of Japan. New York: Academic Press, 1982.

BARNES, Gina. Introdução. In: MIKI, Fumio. Haniwa. Arts of Japan 8. New York: John Weatherhill, Inc., 1974.

BARNES, Gina. State formation in Japan: emergence of a 4th-century ruling elite. New York: Routledge, 2010. 
KIDDER, J. E. O Japão antes do Budismo. Lisboa: Gris, 1970.

KONDŌ, Yoshirō. The keyhole tumulus and its relationship to earlier forms of burial. In: PEARSON, Richard. Windows on the Japanese past: Studies in Archaeology and Prehistory. Ann Arbor: The University of Michigan, 1986. Capítulo 19.

MIKI, Fumio. Haniwa. Arts of Japan 8. New York: John Weatherhill, Inc., 1974.

MIZOGUCHI, Koji. The archaeology of Japan: from the earliest rice farming villages to the rise of the State. New York: Cambridge University Press, 2013.

MIZOGUCHI, Koji. An Archaeological History of Japan: 30,000 B.C. to A.D. 700. Philadelphia: University of Pennsylvania Press, 2002.

OKAUCHI, Mitsuzane. Mounded tombs in East Asia from the 3rd to 7th centuries. In: PEARSON, Richard (ed.). Windows on the Japanese past: Studies in Archaeology and Prehistory. Ann Arbor: The University of Michigan, 1986. Capítulo 7.

PEARSON, Richard. The Nature of Japanese Archaeology. Asian Perspectives. Honolulu, v. 31, n. 2, 1992. 